\title{
INTER-COMPANY CONFLICTS AND CONFLICT RESOLUTION METHODS Results of a Qualitative Research
}

\author{
Eszter BALOGH \\ Kodolányi János College, Department of European Public Politics and Service Management \\ Székesfehérvár, Fürdő u. 1. H-8000; e-mail: besztok@freemail.hu
}

\begin{abstract}
This article reveals the possible connections between the forms of cooperation and the conflict resolution methods in the case of the Hungarian suppliers' - manufacturers' relations. These connections are presented in the light of the results of a research made via interviews. The results showed that in these inter-company connections the companies try to prevent the conflicts by the establishment of long- term partnerships and the connections are coordinated not mostly by the contractual relationship but by the mutually negotiated common rules and trust. Keeping this partnership is a very important intent in the solution of conflicts, however, the unbalanced power relations, the internal organization structure of companies do not always make possible to apply a way of conflict management that could deepen the partnership. In spite of this, the institution of partnership and the type of the supplied products can cause a kind of interdependence that makes possible the co-operative conflict resolution methods.
\end{abstract}

Keywords: conflict, conflict resolution, problem solving, negotiation, embeddedness, interest, trust, reputation, interdependence

In economic sociology, many researches have been carried out about the connection between the economic performance and the social embeddedness of the market relationships (Granovetter 1990). In contradiction with the neoclassical economics, these state that the market behavior is directed not only by the market rules, but the level of trust, reputation and the level of interdependence are also very important elements in the coordination of a transaction. This embeddedness coordinates the connections of the companies and gives a definite explanation what keeps the exchange connections together and how they influence economic performance.

Based on these sociological results, the aim of the research was to analyze the inherent connections between the type of the inter-companies' relations and their conflict resolution methods, by the sociological and market (environmental) factors. This research goes beyond the above facts, as its aim was to find an answer to what circumstances force the parties to brake the connection (they replace each other), or to maintain the relation (whether it is spoilt or not).

First, I introduce the conflict- and sociological theories and research results that explain the elements of the maintainability of inter-company connection and the elements of its limits. Then the hypotheses and the results are going to be presented, and finally, the study is closed with the conclusions. 


\section{HYPOTHESES AND THEORETICAL BACKGROUND OF THE RESEARCH}

\section{Theoretical Background}

Conflict theories of both economic sociology and social psychology deduce the cooperative market behavior from the mutual interdependence of the actors. Interdependence means mutual interest interdependence between the companies, which base on the previous mutual experiences of the actors and on their common current and future intentions; furthermore on the level of trust in the relationship, in what kind of network system they operate and moreover what kind of rules, norms coordinate their actions. Consequently, the limits of the cooperation (the limits of mutual interest interdependence) can be predicted mostly by the help of these variables.

Some managers state that trust is a kind of "glue" that keeps the connections together. This statement means that trust is the basic condition of cooperative behavior. Trust is interpreted by the sociological and economic theories as an institutional phenomenon, which is based on the belief of the actors that their interaction will be continued in the future and it is directed by explicit and implicit rules and norms (Rousseau et al. 1998.). The question is how far and why it is profitable to maintain the confidential relationship; in other words, in what circumstances is it profitable to be opportunistic? The first alternative answer is the threat of the consequences (sanctions), which is defined by Lewicky and Bucker as a calculus-based trust (Lewicky and Bucker 1995, 1996). On the other hand, there is the positive stimulus of keeping a trustworthy relationship when the reward from the relationship is much higher than the associated costs.

This reputation-based interdependence relation in the network system also assumes a strong trust. In this case, trust can be interpreted in a kind of network, where voluntary observance of the rules is generated by the threat of a "sanction", so as the opportunist may get into a trust-lost situation in his whole network and may be the subject of a collective punishment (Grief 1993).

Coordination norms come into existence by mutual experiences and work. Rules are created by negotiation and are based on mutual consensus, and their aim is to coordinate the business community and to legitimate its operation both inwards and outwards; furthermore to offer some protection against the companies that are inconvenient for any partnership (Fine 2001).

The above-mentioned sociological theories describe the frame of cooperative behavior, and those factors that retain from opportunism. This research goes beyond this problem: it would like to find definite answers, what circumstances inspire the parties to give a negative answer to conflicts - that ceases the connections or break them - or positive ones, that maintain them. To answer to these questions, we have to use not only the concept apparatus of sociology but the concepts of conflict theory as well.

Conflict theories work with similar concept apparatus, while the dimensions of the analysis differ. Conflict theories stimulate so-called negotiating situations, in which 
some logical connections are to be found between the characteristic features of conflict situations, negotiating strategies (input) and the possible resolutions (output). From this point of view, there are constructive and destructive negotiating situations and negotiation procedures. In the first case negotiation focuses on the parties' interests, this way the profit, originated from the resolution (both the individual and the joint profit) can be maximized, and, moreover, resolution and negotiation focus on the future connection and not on the present situation; while in the second case the positions prevail over the negotiation process, profit cannot reach the possible maximum, and it is more important to find a solution for the current situation than to maintain the connection in the future. From this point of view, trust is a positive input, a necessary condition for constructive resolution (Deutch 1996). It means interpersonal transactions which may also build or destroy the existing confidential relationship, both at individual and at group levels (Lewicky and Wiethoff 2000). If this confidential relationship does not exist, the solution of the conflict starts towards a destructive direction, it gets escalated and the joint profit of the actors decreases, so the profit of the one party will be equal to the loss of the other, or each of them may come off badly from the situation - a lose-lose situation.

Interdependence can be interpreted in the time dimension. From this perspective, it is worthwhile for the parties to resolve the conflict in a cooperative way if they mutually depend on each another, namely, if they are forced to keep their relationship in the future as well (Krémer 1999). Consequently, compared to sociological theories, in this situation interdependence and dependence can be interpreted according to the possible outputs; namely, when the parties depend on each another they want to find a mutually advantageous resolution, or one with smaller compromise. On the other hand, when they do not depend on each other, the conflict resolution process will start toward a unilateral, profit maximizing direction.

Norms can be originated from the common interests of the parties. If the relationship is important, the parties try to find norms and rules, which are based on common interests, and deepen the relationship and facilitate further coordination.

The fourth positive input - in addition to common interest, interdependence and trust - is the so-called expandable goods. They are external or internal resources that can be mobilized by the partners in a conflict resolution process. They mean symbolic or tangible possessions that can expand the alternatives of resolution in order to facilitate the constructive, win-win resolution of the conflict (Krémer 1999; Deutch 1996; Fisher et al. 1997).

The direction of the conflict situation (destructive or constructive) can be predicted mainly on the basis of the combination of these four factors. When they are not in balance or any of them is missing, the process of profit maximization, originated from the resolution, will be unidirectional (dominant; avoiding; accommodating; or positional conflict management strategy), however, if these combinations are relatively balanced, every partner will take his part proportionally from the process of profit maximization, or in a way that is suitable for him (compromising, constructive or interest-based conflict management strategy).

The supplier-manufacturer connections and the conflict solution strategies can be analyzed by the two above-mentioned theoretical lines: characteristics of partnership 
and the limits of partnership in the conflict resolution. Accordingly, the dimensions of analysis are the following: firstly, what external market environmental elements determine the interdependence or the defenselessness between the actors; secondly, what are the restrictions that arise from the social embeddedness of the inter-company relations that encourage the parties to cooperate with each other; thirdly, what kind of conflict management strategies make possible all these factors together?

\section{Hypotheses}

In the research four hypotheses are set up. In spite of the fact that this research is basically an exploratory one and up until now, no Hungarian research has been made in this issue, it seemed to be reasonable to set up hypotheses and to conduct the research along these four lines. On the one hand, foreign literature and research results gave good theoretical guidance for the hypotheses. On the other hand, according to the researcher's assumption, the types of conflicts outlined in the hypotheses and the relevant conflict management typologies can be handled as "real cases" too, namely it could be also a very interesting result if we found at least some examples for the constructive conflict resolution methods in the Hungarian supplier connections.

Consequently, the hypotheses can be considered relatively elementary (because of the scanty empirical experiences); however, they highlight interesting problems, as they are looking for definite conflict and conflict resolution types through cases.

\section{Market Environment}

The conflict management strategies of the companies mostly depend on the degree of legal stability in the economy, namely whether it is worth for the actors conducting legal behavior (Radaev 2002). The connection between the market and the conflict resolving methods is determined by the intensity of market competition, e.g. the extent of balances/imbalances between supply and demand regarding the products. The third factor is a structural one whether the market positions (strength and sizes) are in balance or not in a given branch.

Lack of legal stability, keen market competition and the structural imbalances provide greater power for certain actors, while others may find themselves defenseless. Power position here means that the extent of its interest interdependence on another company is low, while that of the other - weaker - company is high; and this grants a dominant, dictating position for this company. Planning for the future becomes less important for at least one of the parties; it is not relevant for the superior one. In the resolution of conflicts the dominant, "power over" strategy will be used, which means the unilateral decision-making of the dominant party and the accommodation of the other party to the situation (he is forced to act in a manner he would not do anyway) (Morgan 1986; Dahl 1968). This is true very much in the market situation, where the greater power one company has, the smaller power the other one has; consequently, power is exercised in terms of the expression and consolidation of 
dominance. In a market environment where the market positions are largely imbalanced, some destructive solution processes will start, the maximization of the own profit means at the same time the minimization of the other party's profit, as the parties are not interdependent, they do not have any common interests, for the powerful party the establishment of trust does not bring any extra profit, while for the defenseless party the establishment of trust means higher costs and risk than the award arising from it (Deutch 1996).

This research analyzed this connection in two dimensions: disparity in power, arising from the market structure; and the interdependence or defenseless situation associated with the type of the supplied product. Research focused on power disparity with regard to the connections between the multinational and the small- and medium sized enterprises, as in Hungary today the multinational companies are the most superior ones. The research used two categories concerning the types of the supplied product: serial products and the unique or hand-made products.

According to the hypothesis, the companies with greater market power answer to the conflicts with destructive, offensive steps. We tested this by two alternative explanatory variables. On the one hand, the internal bureaucratic management system of large enterprises is unable to react flexibly to the conflicts arising from market exchange, as the internal organizational decision-making competencies are hierarchical, it means that there is a limited possibility between the negotiating parties for reaching an agreement, because the two parties are not in connection, they do not know each other. The one party on the one side can not negotiate with the other competent party, because the decision-maker is situated on a higher position of the hierarchy. This problem makes the alternatives of resolution restricted and this leads to unilateral decisions against the partners. The other alternative explanation is market superiority, according to which power arises from the weak position of the other party, namely from the fact that he depends on the powerful party. (E.g. the supplier is forced to sell the majority of his products to one customer).

The company which is in a weaker position, in both cases considers the offensive steps as a form of the confirmation and manifestation of power, and this strengthens in him the feeling of threat by sanctions, so he accommodates himself to his customer. This imbalanced situation hinders the establishment of a confidential relationship between the companies: one of the parties - arising from his market position - does not need it (he can easily shift to another partner), or his organizational structure does not allow such a relationship; while for the other party the main obstacle is the high cost.

Behind the categorization of the supplied product there is an assumption that the market supply of serial products is higher; while the manufacturing of products with unique technology or manual work requires more innovation and its market supply is low. As a result of this assumption: if the product to be exchanged is a serial product, the supplier is more defenseless compared to the customer, and his conflict management strategy will be accommodating; and vice versa: if the product to be supplied is a special one, the buyer will get to a defenseless situation compared to his supplier/seller and he is forced to accommodate.

On the basis of all the above we can set up the following hypotheses. 
First Hypothesis

1.1 The multinational company reacts rigidly to transactional disturbances because of his hierarchical operational structure, and applies immediate sanctions.

1.2. The multinational company reacts rigidly to transactional disturbances and applies sanctions, as it has significant market dominance.

1.3. The company that supplies to the multinational customer depends on the customer and adapts to his demands.

Second Hypothesis

2. When the supplied product is a serial one, the tolerance threshold of the customer regarding transaction disturbances is lower and there is a higher probability for applying sanctions than in the case of the unique, hand-made products, where this threshold is higher and it makes him accommodate.

\section{Social Embeddedness of the Companies}

Inter-company connections are directed by informal and formal rules. Formal rules mean the rules stipulated in written contracts. The aim of concluding a contract is to outline the transactions between the actors in order to be able to react for future accidental cases and the future incidents, furthermore, to stipulate sanctions in order to improve the effectiveness of the exchange (Macaluay 1992). Nevertheless, the contracts are not able to regulate the transactions in great details - because of the limited information and the occurrence of unforeseen events -, so some additional coordination channels are required. Therefore, the market actors try to conclude their contracts with great care and with as many details as possible, however, the experiences show (Macaluay 1992; Radaev 2002; Lorenz 1988) that the market actors respect the institution of honor based on conventions (informal rules), and the exchange connections are held together mainly not by the written contractual sanctions but on the one hand, by the so-called reputation based interdependence (network) (Grief 1993), on the other hand, by the market intention to keep the exchange connection for the long run. Mutual past experiences, the institution of partnership and loyalty depend on the institution of "friendship" and acquaintance, so they are an informal guarantee for the cooperation, as well. Empirical researches showed that it is much more difficult to reconstruct trust that was based on friendship or good acquaintance than institutional trust (between companies, institutions), where the repeated or serious conflicts generally lead to the final interruption of connections (Lewicky-Wiethoff 2000).

The partners try to diminish the possibility of conflicts arising from the exchange by stipulating the general norms regarding the quality and fulfillment, as well as the special criteria concerning the exchange; and/or during their long-term cooperation they establish the norms that outline what is allowed and what is not allowed in the given relationship. Consequently, there are fewer conflicts in a long-term market exchange connection, because the relations of the actors - during their accommodation to each other and during the negotiation (Fine 2001) - are directed by formal and informal coordination norms. The elaboration of norms and rules is of common interest, which influences the improvement of future performance. 
The common past and the future intention determine the alternatives of conflict resolution as well. Since it is very long-lasting and expensive to find a new, reliable and good partner and to establish a good business connection (a common learning process), and, moreover, it is difficult to obtain and to grant trust to another partner, the actors make efforts to find a good solution for the problem and they do not want to exercise sanctions immediately or brake the connection. In this respect the research by Lorenz (1988) and Maculay (1992) also pointed out that the companies are willing to go to the court and to consider a conflict as a legal case only in very exceptional cases, on the other hand, it happens several times that the problem as a question cannot be handled by law. When the exchange partners have got positive experiences about each other, they are probably willing to mobilize extra efforts and resources to find a progressive solution, even if the price of keeping the contact is high at the given moment.

As a whole, on the basis of all the above it can be assumed that trust (that can be based on friendship, acquaintance or may be developed between institutions), reputational interdependence, the coordination norms (that are based on common interests and are created by negotiation) can all have originated from a common "history" and they create a kind of interdependence between the parties (joint projects, investments, etc. Lorenz 1988). Consequently, the partners try to resolve their conflicts along their interests, instead of spoiling their relation, and they try to find a solution that is suitable for each of them.

Considering the above, the following hypotheses can be outlined:

Third Hypothesis:

When there is a long-lasting exchange connection between a supplier and a customer, it is very rare that they have conflicts arising from the non-observance of their obligations; however, in case this occurs, they will solve them jointly, by negotiation, as they are not interested in ceasing their relationship.

Whereas when there is an ad hoc or short-term relationship between two companies or this relationship does not have a long past, in all probability they will apply sanctions against each other.

Fourth Hypothesis:

When the relation between the partners is good, they try to solve the conflicts by negotiation and with patience, even if this represents some risks for them.

On the other hand, when the relation between the partners is bad or it has not deepened yet, they do not make efforts for the joint settlement of the problems even when the conditions for such settlements are given; in this case there is a big chance that they apply sanctions against each other.

\section{METHOD OF RESEARCH}

Research was made between 2002 and 2003 in Budapest ${ }^{1}$, via structured interviews, for exploratory purposes. The results on representative sample could not be its aim; however, this does not diminish its value because they can facilitate the

1 The research was supported by the Julius Rezler Foundation. 
performance of a future, more detailed research. So, we did not intend to draw any far-reaching conclusions, in this way the research highlighted interesting and thought-provoking facts, instead of general conclusions. As a whole, 8 interviews were made which could give relevant and useful information. Points of view of selecting the companies followed the logic of the hypotheses. The interviews we used for this work were made at the following companies: at a holding company, at a medium-size company operating in the electronics branch, at a multinational company operating in the electronics branch, an industrial company manufacturing railway accessories, a company manufacturing instruments and accessories, a German-Hungarian joint venture dealing with hydraulic elements and its two supplier companies. The companies were chosen partly from the publication Cégreferens (company reference), partly on the basis of personal acquaintances. First, the companies were contacted by phone, then, when we entered into contact, the interviewees were given a short (one-page) information material about the research. If during the first conversation no date could be fixed for the interview, the partner was contacted again by phone, on the second or third day after sending the information material to him. At the selected companies we asked the colleagues who were aware of the supplier/customer relations of the relevant company, coordinated these relations and/or maintained a direct, everyday contact with the partners. An interview took about 1-1.5 hours.

We faced several difficulties during the interviews, as the cooperation and openness of the interviewees was not always satisfactory. They often referred to business secrets and lack of information. The least willingness for cooperation could be observed at the multinational companies and at the suppliers to multinational companies.

\section{RESULTS OF THE RESEARCH}

\section{First Hypothesis}

\section{Organizational Restrictions}

Interviews showed that the multinational companies conduct a rigid, dominant conflict management strategy towards their suppliers and this can be traced back to their internal bureaucratic operating system. The first alternative hypothesis was verified. This means that the rigid reactions to the performance disturbances may arise not only from their power but from the internal organizational structure, as well. The interviewees made the following statements in this respect:

"...Here the observance of the rules by the employees is different. So, this is a rigid relation, here our human connections have a different nature ... it takes a rather long time to run a question over the organization. Here we are not in direct contact with the bosses and the owners, so everything is longish and complicated. If we were in connection with them, everything could be resolved quickly. An immediate decision is made and we can sit down to discuss the problems."

From the above citation it can be seen that for the small and medium enterprises who supply goods to the multinational companies the greatest problem seems to be that 
they are not in connection with persons who are competent in decision-making. It means that in case of any conflict the contact person is not in a position to get to any agreement with the suppliers. According to the conflict management literature, one of the most important conditions for constructive, cooperative conflict management is to ensure an opportunity for discussion between the "parties" who are competent in the decision-making process, namely who are allowed, authorized to make decisions and who are interested in this decision making, namely, who are able to execute decisions. (Krémer 1999). In this case one of these two parties is missing; one of the parties plays only an indirect role in the decision-making process. Consequently, the resolution of the conflict cannot be - or there is only a little chance that it can be-constructive. If we consider the possibility of profit maximization of the companies, in this situation there are two alternatives for the resolution of conflicts. If it is not important for the superior party to maintain his relation with the supplier in the future the conflict may be resolved by its force, which means that the profit of the multinational company is equal to the loss of the supplier. On the other hand, this may lead to some common losses because of the longish decision-making procedure. This is true also in the case when we consider that a big company or a multinational company will probably not be destroyed totally by a delay or a mistake, because they have adequate reserves, while a smaller customer does not have such securities. Trust between the exchange partners arising from the above conditions - is established first of all at an institutional level, where the confidential relationship is based rather on smooth transaction than on interpersonal connections: "This is a different human relationship".

Organizational rules drew our attention to one more interesting question. The rigid reactions of the multinational companies are justified not only by the longish procedure of running over a problem but by the impeachment practice applied for the employees, as well. This was explained by one of the interviewees in the following way:

"Every department can hire suppliers only at its own responsibility. He can say that he insists on this supplier only for this supply or project. And at the moment when this statement was made it is put down in writing, and from this moment onwards this company is to bear the responsibility. In this case, if this supplier causes any damages, responsibility is to be borne by him and I rather do not say anything about the consequences now... even if he is the only one who can supply this product, this is the rule here."

The above citation shows that the employees are impeached on the basis of a strict order. When a transaction can be carried out only with one certain supplier, the competent colleague is to be blamed; he is responsible for the mistake or problem even in this case, too.

\section{Market Superiority}

From the interviews it turned out that the superior companies in certain cases deliberately created conflicts in order to make advantage of the transactional problems or simply to strengthen their power symbolically by forcing the weaker party to accommodate. This does not mean any sanctions that, for example, they consider the matter to be a legal case and turn to the court, or they apply the sanctions stipulated in 
the contract, but they outline additional expectations that can be fulfilled by the supplier only with difficulties and by much extra energy. For example: when the customer has a quality complaint, e.g. regarding the package, part of the suppliers adopt to this special request in $100 \%$, even if this was not mentioned either in the written contract or in the verbal agreement. The following citations highlight this aspect:

"...they do not accept from us what they accept from themselves. This means that when a production comes to us we see what they do there but they do not accept this from us."

"Accidentally we approached to the question in another way, at already the beginning we could feel that they found fault in everything. One of their objections was that when we had supplied painted accessories to them we had packed the products to protect them from any damage. And they said that they had had no time to unpack them."

In the above case the thing was not the ways of conflict resolution but a conflict generating process, with the aim of consolidating power. This market behavior does not assume any intention for the elaboration of a trustworthy partnership. The customer is in such a superior position in which for him trust is an irrelevant factor, while the supplier is so defenseless that for him only the profit is important and does not make any special efforts to establish a confidential relationship. So, during this transaction the supplier only tries to avoid sanctions.

\section{Accommodation of the Supplier}

The interviewees drew attention to the versatile and interesting cases of accommodation to the customer. They emphasized the following cases on the customer side:

“...this company has a very great prestige. To be the supplier of this company is a good reference to us..."

"...we have a partner which has partly changed his profile for a time and he manufactures products for us even with some loss, because it is a great fun for him to supply us and he is loyal to us"

"...I think we try to achieve what we see from the ....world, this is a payment term of 90 days, which is very long and very few suppliers can tolerate it. Those with whom we have established and maintain a long relationship will obviously try to fulfill this condition."

"...imagine that our accessories are in each of the engines."

From the supplier's point of view, these citations draw attention to three important sources of power: prestige; the supplier's dependence on the customer and the market share. The first point highlights a very interesting feature. Namely, the supplier company does not terminate the connection even if it brings financial loss for him, as the putative or really symbolic gain, reward arising from this relation is higher than the costs of the maintenance of the connection.

The three sub-hypotheses of the first hypothesis were only partly verified. When the market environment (supply and demand of a product) dominates the business connection and there are no other circumstances that could create any kind or form of 
interdependence, the superior party (this superiority may arise from his market share, personal prestige), will demonstrate his strength and by applying a dominant strategy he generates conflicts in order to consolidate or strengthen his power and to make the weaker party accommodate. However, this strategy does not make the inter-company connections fragile, does not lead to the termination of the connection or to the application of other sanctions, which can be explained by the accommodating strategy of the supplier. The supplier is not able or does not want to terminate the connection, no matter how expensive it is for him, as his dependence in the market is very strong, therefore, either voluntarily (when he uses the customer as reference) or by necessity (when his future existence depends on the customer) he accommodates. The other reason for the dominant strategy of the customer is that the conflict is to be resolved not at an individual but at an institutional level. Conditions for the interpersonal conflict management are either not given (conflict management runs not between the competent parties), or the individual responsibility of the customer is very big. Negotiation and constructive conflict management are not possible, as the customer is able to handle the case only at an institutional level, in a rigid way.

\section{Second Hypothesis}

Type of the Product

One of the most interesting experiences of the research was that there is connection between the type of the supplied product and the interdependence of the parties. The hypothesis was verified: if the market supply of the product is little, the patience and tolerance threshold of the customer is higher. This influences the contractual terms, too. For example: the customer who acts strictly with his suppliers and sets up keen competitive conditions, will get into a defenseless situation against his supplier who manufactures an absolutely specific product, so his tolerance threshold gets higher. This is the case when the supplier plays a dominant role in the conflict and the customer is forced to accommodate, to amend the contract, and he includes the potential disturbances into his own performance calculations.

"...They are the only partners of ours with whom we are not satisfied, but unfortunately, we cannot do anything. ...There is no other company which could replace them. And they are fully aware of this fact. It often happens that they are in several months' delay, life stops at us, and there is a deadlock ... However, now I already know what to do with them. I already know that they are late ...I know how to calculate and I make my plans accordingly. We have amended the contract and I won't say that our relation is cloudless but at least I do not have any inconvenience from this ...... and they are aware of the fact that they dictate, it is impermissible ..."

“...there is one company and although we are in good relationship there are several problems. More exactly, there were several problems, we accommodated to their delays, to their unreliability. We cannot do anything with them, as it is impossible to replace them with any other partner. Sometimes they were several months late with the delivery. Now, both in the contracts and in our own work we include these delays. In this way there is no dispute now, however, we still feel some tension." 
Compared to the first hypothesis, the positions of the actors are exchanged: even although the customer has market superiority, he is not in a position to apply any sanctions in the case of a specific product; he cannot endeavor to consolidate his power, as it would cause big difficulties or it is impossible to replace his supplier. On the supplier's side this does not necessarily mean the application of a dominant strategy. Problems arise in connection with manufacturing of the product, so in case of unique orders it may happen several times that even the supplier himself is not able to predict any possible delay or other problems.

When both the supply and the demand are low, there is interdependence between the parties. Such products are the non-serial products, the special, hand-made products or the products requiring specific professional skills and/or instruments. Some opinions from the interviewees:

"...We receive the order, deadline is stipulated in the contract, so what? Now, for example, no raw material is available, there is a standstill in our work. They are indignant at us; nevertheless, there is no material. In other times we had to prepare the tools, as you know, it is not the case at our company that when we receive an order we immediately start up the machine and the material is streaming out. Not at all. Generally, we work with specific tools and this takes time and costs money, doesn't it? But they do not always understand this and then they make a fuss .... and I say bye-bye, you may try to find an other supplier ... but I cannot quarrel much, either, it is not good to go too far ...they are important customers of ours and if something happened to them, I guess this would put us into trouble a bit ... We are in delay and they threaten us that they won't pay."

This case shows that a specific product should establish real partnership between the companies. There is no alternative for them but getting to an agreement, as both of them can lose much if they terminate the connection. Despite of this, none of the interviewees mentioned any kind of behavior in this respect. Each of the interviewees spoke very negatively about this kind of conflict. On both sides a specifically destructive, offensive negotiating strategy is applied. This result is rather surprising, as every economic sociological and conflict theory says that interdependence between the parties, in all probability, induces cooperative behavior and negotiation strategy from the actors. In principle, in such cases basically trust is the most important factor in the connections and it should be manifested not only at an institutional but at an interpersonal level as well. Furthermore, it is the special interest of the actors to establish flexible formal and informal rules, norms that coordinate their work. Besides, it is their common interest - owing to their total interdependence - to conduct both the current and the future transactions smoothly, as they cannot replace each other, so they should negotiate along their interests and resolve their problems with joint effort, by mobilizing extra resources. In these cases constructive conflict management could be aimed not only at problem-solving but at prevention, as well. In the research there was no opportunity to test the reason of this phenomenon, but in all probability it can be explained by the fact that they are not familiar with constructive negotiation techniques and procedures.

This hypothesis did not take into account another very important variable in the explanation: the geographical, regional trammels. The customer may become

Review of Sociology 11 (2005) 
defenseless if the manufacturing of products is restricted in certain areas and it would be more expensive or quite impossible for him to work with another supplier.

"... the question is, how much enforced I am to hire him, because it may happen that cables are being laid down somewhere in the countryside, for example in the steppe. Therefore, I may be forced to hire that company for the work because no one else who could do it can be found there, either near or in the district..."

\section{Third Hypothesis}

\section{Length of the Connection}

Each of the interviewed companies is in a long-lasting connection with his exchange partner. Long connection was interpreted by them as a basic condition for economic survival and good reputation. Furthermore, their justification for the necessity of long economic connections was that under the Hungarian market circumstances they had been unable to be competitive actors in ad hoc and/or short business connections and, moreover, with this kind of business philosophy they had been unable to find suppliers or customers for themselves. The interviewed companies have established their partner relations in many years and actually they built their business survival on these connections. They are reluctant to change these partnerships or to replace the old partners with new ones, as it would mean a greater risk to find a new customer or supplier and would require much effort to learn this new situation and to get accustomed to each other. One of the interviewees said the following in this respect:

"You see, nowadays it is impossible to think for short term. You may think for short term, this is a kind of life-strategy, too, but not in the industry. I could not tell an example where it applies, probably the manufacturing of decorations for Christmas trees, where I say that I have made a certain quantity, some more would be needed but I'd rather do it at another time or next year, I don't care. I have earned my money, let the decorations be hung up to the tree if they are needed, and next year we will come again. But industrial activity is quite different, where one must think and calculate for the long run, provided that he is dealing with a serious industrial activity ...."

Nevertheless, partnership means unbalanced power relations because of competition among the suppliers and of the high expectations of customers. And this is true in spite of the fact that the customer companies established a list of suppliers including companies which had already proven their worth and the customer trusted their performance. None of the interviewed companies maintains such a business relationship with his partners that might be called classical business alliances or strategic connections. They did not have any joint innovation, development or any cooperation that could diminish keen competition a bit. We asked several times and in several forms whether only some germs or elements of strategic relationships had appeared in these partnerships. We could not find any relation of this kind, either in their market ideas or in an explicit form. Even the demand for this was not mentioned by any of the interviewees. In principle, this may have two reasons. One is that thinking/idea of an alliance is relatively unknown; this was also indicated by the fact 
that the interviewees were not really aware what it meant. The other alternative explanation is that although their connections are long, the realization of common interests and their implementation in practice are not part of the market mentality and culture. This is confirmed also by the fact that the companies do not incorporate mutual guarantees into their written contracts (e.g. retainer). This is illustrated by the answers of the interviewees in the following way:

"...I say that these companies, who order do not care at all, how we do it. We give a quotation, our work is good, the work pieces are picked up, the quality is good, and if this costs money for him, he will go to another company."

"... well, we make our own developments for each of them, in order to be able to satisfy their requirements and that's all. These are at least ours."

"...well, it is a bit strong that common development, but there are solutions which are found out during a common consultation and we perform the development. For me common development means that we conclude a written contract for something."

The concept of "long cooperation" was interpreted by the interviewees in a rather versatile way and in many cases they did not even name the concept. They mentioned good relationship or long-term business connection, instead. This could be observed in spite of the fact that from the interviews we could hear many examples of "classical" cooperation, partnership.

"...We know that they will expand their production in Hungary. They practically share their visions with us, so we will buy machines of higher reliability and higher accuracy, bearing in mind that after 3-4 years we could be asked ... to cooperate with them in the manufacturing of elements, as a supplier ... these are our calculations for which there is no guarantee ....a verbal information."

"....so there are some parts that we manufacture for them. They order them in advance for six months, or they only indicate it and they punctuate the schedule of call-off only later ...look, this does not mean too much, we may even lose the business ..."

"... and the annual draft contract is assembled... and practically in the next year there is no significant difference, only if a new product comes, it may enter. So something may be introduced but we cannot rely on it in $100 \%$. We may spoil it, this is only a theoretical thing, because such thing has not really happened to us, and you see, our relation is good, too ...."

Consequently, a long-lasting connection does not mean cooperation stipulated in a contractual form, but it means a verbal agreement or an implicit agreement about future cooperation, namely, that we "rely on each other". Trust directs the connections in an implicit way. Contracts are renewed annually and the conclusion of a contract is preceded by a long negotiation procedure, during which the companies re-discuss the conditions of exchange. The customers issue a tender invitation for the potential suppliers at the beginning of each year. These contracts are master agreements which stipulate the annual quantity of the orders, prices, deadlines and in case of non-fulfillment the relevant sanctions, namely they contain only estimations; the daily exchange is done on the basis of the actual (daily/weekly etc). call-offs. Consequently, in the contracts only the minimum conditions, terms of the transactions are stipulated in a "standard" way and nobody mentioned any common guarantee systems or securities that could be mobilized in the case of any problem (Maculay 1992). With 
one exception, all of the companies emphasized that they did not make any verbal agreement; everything was put down in paper.

"...the suppliers are subjected to very hard competition. In case of a new product both the well-known and the prospective suppliers are asked for price quotations and delivery terms. The result is always an annual contract, and another benefit is: when the contract was concluded at the end of the year it is sure that we can count on the order in the next year ...We are under a continuous price-press and this requires the permanent development of technology, we are all the time racing against the price ..."

Contracts stipulate only the very formal market rules, related to the exchange. Sanctions are also handled formally, none of the interviewees mentioned that prior to any litigation or penalty a kind of negotiation forum for settlement would apply. Contract plays a very important part in the competitive and price policy, however, the relation between the parties and the period of their cooperation are determined by other factors and not by the written contract. The main thing from the point of view of good connection between the parties is trust, besides the written contract (Lewicky-Wiethoff 2000). The interviewees made almost unanimous statements about the connection between trust and the conclusion of contracts. Below there are two examples:

"...Contracts are not dictated only from the power side ...there is nothing in the contract that could be fulfilled only reluctantly. We are in an absolutely normal position that serves the interests of both parties ... It is stipulated in it that delivery deadline should be observed. In case we cannot deliver in time we have to send a notice that we have some problems and inform the other party how we will solve it. The terms of payment and such things are also stipulated ...in this case we decide by mutual agreement when the payment is to be effected ... the most important is reliability, for example, that we always deliver good products in due time. Their reliability is conducted by the market. So, if the market conducts their products and I get a forecast and they cannot fulfill it because business does not go to him for some reason, he will not call me so often, such is business ... but when everything goes smoothly, then it has some antecedent. I'd say that we count on each other. So we count on them that if they have any problem they will inform us in good faith and in due time. Here I mean also that, for example, we have the annual forecast, but they see that this cannot be fulfilled and they do not let us run the risk of investing lots of money into the material ..."

",... and it is a real value when somebody is a reliable supplier for a long time. In other words, this means that if somebody is in partnership with a company and supplies them with high quality goods in a reliable way, they would not conclude a new contract with another company."

The above citations draw attention to two important things: when the customer does not need the goods he has ordered, he pays the price and does not order any more, but this is called cancellation of the order and not breach of the contract, furthermore, the exchange is conducted by trust and not by the contract. We received similar answers from the interviewees to the question: what is most important for you, to feel confidence for your client and how can trust evolve in these connections? The most important criteria were reliability and flexibility. Reliability means accurate and high quality production from the side of the supplier and due payment from the side of the customer. Flexibility first of all indicates the 'just in time' system and that they are able to satisfy the new demands of the 
customers soon and in a good quality. The criteria of correctness and straightness were mentioned many times, too. Here both sides emphasized that in case of any problem they mutually require an immediate notice from the other party; and require a straightforward behavior that the partner does not play them off against competitors. These factors are so important that they have priority to the price when partners are chosen. Price, as they state, is only a secondary factor in the selection. This shows that the companies build their business future onto long and reliable connections and lay great emphasis on trust in each other. The interviews highlighted the phenomenon of the so-called calculation-based trust, namely that trust is based first of all on correct fulfillment, while a good personal relation is only the second criteria. Trust plays so important part in the transactions that it is represented as a preventive guarantee in business relations. Trust is based on ethical norms and is developed by mutual positive experiences of the past, so the actors are not interested in behaving opportunistically. In this context interdependence is built on the common past and plays a very important role in the practice of tendering and contracting. For parties entering into market exchange, trust is vital not primarily in conflict management but it represents a guarantee for avoiding the possible conflicts as well.

“... Look, we are people, we are subjective creatures and when we sit down to negotiate, our personal relation influences the negotiation in some way, but this is not the main point ... it is the performance of the company in the previous year. And that we don't have to worry, because if this company has fulfilled his obligations honestly for several decades, then we can rely on them in the future, too. Somebody may be appealing or not appealing ... I think this does not matter too much ... When a business goes smoothly, it always has some antecedent. Namely, we count on them that if there is some problem they will inform us in good faith and in due time. I mean, for example, that there is an annual forecast, but they already see that this cannot be kept and they do not let us run the risk of investing lots of money e.g. into material. Because it makes different how long we sit on the material. Only some weeks, instead of three months ... Such a connection system also exists, what is natural on one side probably might not be natural on the other side. I don't know."

An example was mentioned by one of the interviewees for the other aspect of interdependence between prevention and trust:

"...well, not all customers are the same type. For example, for an unknown customer we stipulate shorter delivery deadlines. When the company is absolutely unknown and we have some doubts, we specify that they have to pay in cash when the goods are ready."

In a connection where trust has not been established, where the market actors do not have any history, they incorporate extra guarantees into the contract, and the dominant factors in the coordination of the relation are the contractual elements and not trust or any ethical norms (Halpern 1994).

If the market laws, the very keen competition and the annual tender invitations are concerned, it could be a logical consequence, that in case of any problem the parties could exercise immediate sanctions or could cease the connection. However, the facts contradict this assumption, although this does not mean that no certain informal sanctions are applied by the parties against each other or that they would have a wide tolerance limit. They have to solve conflicts very quickly and effectively and this can 
be achieved only by negotiation. On the other hand, the establishment of a new business relationship takes too much expense and it is not worth solving a conflict immediately by the termination of the connection. Negotiations are considerably facilitated by the fact that the partners have common norms and rules in their connection, which are interpreted in the same way by both of the parties: namely, it is clear for everyone what reliability, correctness, etc. mean (Horne 2001).

Let me mention some examples when the sanctions stipulated in the written contracts are applied by the parties against each other. It must be noted that the interviewees - sometimes more, sometimes less definitely - stated that they had not met any serious sanctions during their business life. As a whole, they mentioned only one form of sanctions: to withhold payment, however, it cannot be considered as a "classical" form of sanctions. In the interviews first of all the actual transactional disturbances (problems with payment, with the deadline and with quality) were mentioned as typical conflict situations. Delays in the deadline were caused first of all by quality or technical problems or complications. Payment was withheld when the ordered product did not arrive in due time or in the specified quality.

"...these are nuances; do not think that you will get a rectangular one instead of this one. But in this sphere the things go like this: there is a specification, this is scriptural, cannot be altered and that's that! When they find that the product differs from the specified size but they can use it, then it is practically good, they will pay its price. If it cannot be used, they will not pay for it ....yes, we had such a case, it already occurred."

In summary, there is connection between the past of a business relationship and trust, as trust has a preventive function. The partners do not change their long-term business relations to new ones, as they know that in this way they can prevent inconveniences. Caution is so dominant in business connections that in the practice of tender invitations reliability and flexibility are even more important than the price. We did not find any example for the second half of the hypothesis, there was only one indication to the connections of this nature. In case of the short-term or ad hoc engagements business connection is coordinated by the written contract and not by trust, and although we did not receive any example for this, presumably the probability of the application of the contractual sanctions is higher, since the future of the business relationship between the parties is not important.

\section{A Contradictory Example: Lack of Trust in the Market, Cross-debts}

We met only one single case, when the parties did not act honestly in conflict resolution. This case is special and therefore interesting, because as the interviewee said, they have a practice that they conclude contracts for obligations about which they knew even at the moment of signing that it could not be fulfilled. This company mentioned the system of the so-called cross-debts, which is an established and normal custom in their business life. Their activity is embittered by the delays of their own suppliers and by the delayed payments of their customers. The company manufactures accessories that require very special and manual work. There are also very few companies in the market - and they are mostly of state interest - which would buy such 
accessories. The citations below give a good illustration of the company's situation and show how non-observance can escalate in a whole market and how demoralizing it can be. From the citations it can also be seen that the relevant company owes first of all to his ad hoc and small suppliers, which indicates that probably he cannot afford such a behavior in his more important and long-lasting business connections. On the other hand, it is remarkable that he acts in the same way with his small, defenseless suppliers as his own customers act with him in a similar situation. Furthermore, this case is special, because it is dealing with the manufacturing of so special products for which there is neither a big supply nor a big demand in the market.

"...This is the case when I usually say: put your foot into the doorway to prevent your shutting out ...in this case I have already got inside, and we may quarrel later, when I refuse to deliver. This is a trick. I do this, too. ... In this case he cannot go up to a customer and tell him to buy a different one ... so he does not cancel the transaction, as he is not so fool, and generally these projects are made with some safety margin. This is not fair what we do, but others do the same with us, too."

"...we have lots of suppliers, several hundred. There are both big ones and small ones among them. ... These debts concern first of all the small ones. There are various types; usually the small ones are the most upset. We owe mostly to our ad hoc suppliers with several " $X$ "2 millions...We usually circum-compensate in this situation ..." $X$ " owes us, we tell him or our customer that somebody ordered "Y",3 pieces of "Y", so we ask him to pay it directly to the supplier, or to transfer the advance money to this or that company, so that we could not spend it. This is a hard thing, people are getting more and more indignant at us today, this regards both our suppliers and our customers, as we are in delay because we are unable to pay.

But we ask the Englishman: how long is your delivery term? He says it is 5 weeks, then, about three months later he says well, now we are ready. And now they are furious that they have to pay penalties because the total trial operation would have been started up."

"...Penalty is stipulated, however, it is never collected ... Everyone specifies which paragraphs of the Civil Code shall apply but they do not ever use it. Now we have a rigorous contract with " $\mathrm{X}$ ", but we had found out that we were not in a position to fulfill the contract in due time because the contract had not been approved in due time. We had talked at large and finally we did not have to pay anything ... They will not receive this at such a cheap price from anyone else ... and nobody means harm to himself ... We were late with delivering the first " $X$ " they raved and stormed where the shipment was, nevertheless, they ordered the next "Y" from us, at the most they will grumble that it is not ready in due time. Their company is twice as big as ours and they do not pay in time, either. I am sure they do not kick up a shindy because they also know that they won't pay it in time."

2 Name of a company

3 Name of a product.

Review of Sociology 11 (2005) 


\section{Fourth Hypothesis}

\section{Relation Between the Negotiating Partners}

In the case of the asked interviewees, personal trust has less importance in business connections than the form of trust we discussed above. From their point of view, a good personal relationship is very important, however, it did not turn out to how far and in what form the negotiating parties dare or can bear the risk in the conflict situation.

Here I mention some inverse examples for the importance of interpersonal relations. Almost all of the export suppliers complained of their foreign partners. These complaints concerned the difficulties in communication and problem management, which originate from the geographical distance between the companies, while, on the other hand, frustration against the foreign companies could also be well detected. It was not infrequently that they had mentioned these business connections as negative examples, compared to their positive domestic ones. I list here some citations, only as curiosities. They highlight very sharply, how big inferiority complex and many times - antipathy the Hungarian entrepreneurs feel towards their foreign partners. Distance creates obstacles between the parties, which hinder the development of trust, this way the transaction between the parties really does not mean anything else but business exchange, the future of which is uncertain. These cases happened mostly with the smaller Hungarian companies, whose main profile is not export; and with entrepreneurs, who have recent foreign business experiences.

"It turned out that for " $\mathrm{X}$ " the material is not enough, we had to buy material with bigger diameter. In the meantime in Hungary the protective duty was introduced for "X" materials, so I told him that this had caused a $20 \%$ price increase at us and I would like to enforce the arrears. After two months I called him by phone, I told him my problem, oh, indeed, I will revert to the matter on Friday... on which Friday... oh, this week, he says... Whenever I called him he was not available and I said that I would not deliver until the settlement of this matter, but he does not even remind me of it, this is preposterous. Many times I feel he says that this is still Eastern Europe... “"

"They pay posterior and they still owe us EUR " $X$ " from the previous shipment and I won't deliver the rest of the goods until they settle their debt. It was interesting that they had started to object to our products, the " $X$ " we deliver is not good. One of our employees called on them, they measured the product and it turned out that it was good. He can buy it only at a considerably higher price and in spite of this he was not willing to pay the " $\mathrm{X}$ "\% rise, either. I thought that in this case I won't force this thing. I don't know what the reason for this can be ..."

"It is doubtless some personal relations are established at the big companies and in this case the connection is very good ... There is a contact person who we belong to, therefore, a personal contact evolves between us. We have one at "Y", too, we know who he is, however, because of the greater distance it is rather impersonal. I had to fight a lot when we brought the work from "Y", as, I emphasize, we did it cheaper and better..." 


\section{Further Results of the Research}

\section{High Reputation}

This research, beyond the problems worded in the hypotheses, pitched upon a further curiosity. In spite of the fact that in the literature we can read many times about the importance of reputation, this issue has not been found in the hypotheses (Raub-Weesie 1990). This research has pointed out its importance and its unique nature very sharply. Namely, connections between the companies and conflict management mostly depend on the market prestige of the given company, and the extent of the reputational interdependence between the partners. The high prestige of a company could balance the unequal market position, since trust could be a consequence of a selection mechanism as well. According to this there is some market selection mechanism, which selects the actors of some business group. Trust here means that someone is a member of this group or not, because membership means a guarantee for honest and good work. For example, it is very difficult to get into the 'market elite'; however, if someone is already there, it represents guarantee for honest and trustworthy behavior.

We met only one company which is the member of this 'market elite'. The leader of the company characterized cooperation in the following way: this concept can be imagined only between business partners who manufacture in high quality and who buy high quality products. In his opinion the 'supplier' cannot be a party in cooperation. When the partners are equal, they are in a seller-buyer relationship. The interviewee worded this as follows:

"This is a simple buyer-seller relationship. In my view a supplier to Hungary is a company that is forced to deliver to a multinational company in Hungary. This is the supplier. We do not belong to this circle. There is no such thing abroad. There is a seller-buyer relationship instead. A supplier does not have quality and does not have price, he is a "slave". The seller-buyer relationship is a mutual relationship. They can resign from it. A supplier never resigns. But I have already done so."

For this company, a written contract is an absurd thing, as according to him they have such a high prestige in the market that they stipulate only the small details of a certain action in writing. This was the only one company which said that in case of any problem they would try to find a solution jointly with the customer. Verbal agreement assumes very strong trust between the parties. Non-fulfillment of the agreement would mean the loss of trust and credit in the prestige of the company and this would spoil his relation not only with this certain partner but with other customers as well. This interviewee explains trust with the inviolability of the business etiquette followed by his company and by the companies cooperating with him. Consequently, the interviewee here speaks not of trust but of etiquette (and this could be called norms, too), and of the small group of companies with high prestige and reputation ("market elite"), that protect these norms.

"...we are too highly qualified. Our products are being patented. Now we manufacture products which cannot be manufactured by other companies ... for example, now the telephone rang, I am in contact with the leader of " $\mathrm{X}$ " company and I receive all the internal data. There is no tender invitation. We could manage to achieve 
a prestige that he need not have to worry, he will receive everything in time and in due order ... Look, we have an idea for 10 years. In the great majority of our business transactions we have no contract ... Personal connections, so we have no time for a contract. We have very few transactions that are stipulated in a written form. The data required for the daily work are recorded in a written form. This means that we know what shall be done today and tomorrow and how much we will account to each other. As regards the things that are for a very-very long term, we have a piece of note, but this has no importance. The point is to agree that we will do this and this together and then we will see the result. These things work on the basis of trust; however, he cannot take it to anywhere else, because if he wanted to take it to somewhere else I would see it. These things cannot be taken away from one day to the other."

"... With its 30 percent market share, this company is a big one ... actually, he thinks that it does not improve his reliability or high reputation if he fails to pay. Unfortunately, in Hungary the jerkwater companies, and not only in Hungary but all over the world, the jerkwater companies can afford not to pay."

In conflict management both partners are coequal. Probably, it is not an exaggeration to state that in this case transactional disturbance does not represent a conflict situation for the parties. From the interview it has become quite clear that this form of cooperation (which means real partnership) and the problem management system can exist because there is an implicit order of selection in their market. Both the suppliers and the customers work only with companies which are "worthy for cooperation". This was illustrated in an interesting example by the story about international fairs.

"... This resembles to the thing that up till now I have received a new partner always on the basis of the existing personal connections. The other thing that works is the professional fairs ... Prestige is created by quality. The company must be reliable. And this has a price ..."

"...I am irreplaceable for him and this is true vice versa. I think it is not worth him, either, losing a partner with high reputation. This is not the interest of any of us. Delay has never occurred .... quality problems have occurred, yes, ....no, sanctions have never been ... As regards payment, it was always fulfilled in due time, this cannot be a question. First a company has to prove that he is not incorrect, then the other things will follow, this is our quality assurance system ... If I realize any incorrectness on their side, and I have to say that up till now this has not occurred, yet, I will say it to him and we will discuss it. If we cannot get to an agreement, I consider grinning and bearing it, in the interest of future business transactions. This is my life, and it is not indifferent for me what partners I have, you know. Which companies I can list as being my partners. But up till now such a case has not occurred, yet, as I do not start business with negligible companies and they do not start business with no-name ones .., it had already happened that I sent away a customer but this was a rather absurd, atypical situation"

Here we could hear reference to the so-called expandable goods. Naturally, this does not mean that there is a clear and close connection between reputation and the expandable goods, and it does not mean, either, that the partners mobilize some resources for the solution of the problem only in this context, but in all probability, it was raised just in this case. On the other hand, it can be stated by all means, that the 
company's prestige in the same time represents guarantee that the parties have enough reserves they can mobilize for the solution in case of any problem. Besides, it can be assumed that compared to other cases, conflicts arise quite rarely, the parties endeavor for a long-term agreement and the chance of its implementation is higher as the extra reserves are available and they are used as well. Furthermore, the parties control each other in an informal way, in order to protect their high reputation and their own business performance. This good 'image' and high performance encourage these companies to solve their conflicts between themselves; they do not disclose them to others; so they try to settle the conflicts jointly.

"...Miss, we do not refer to anything. Anything at all. We just sit down and try to reach an agreement. In serious connections we always accept the other partner's problems. He too, and me too. And he rewards this in some way. He either pays or I get something else instead. Up till now we could always solve it. ... I have to understand then what his problem is ... What is the thing he can accept? For example, this means that when the transporting agent is late, he pays for it the wage for Saturday and Sunday. ... Yes, this is due to my person, to my staff, we are the guarantee, the company ... oh, no, we do not apply any sanctions, and I have already told that this is not worthwhile for any of us. Look, this is like family life. When we have a problem we settle it, we sit down and discuss it. Don't do this any more. This does not mean that we have no daily problems. This does not mean that at home I don't say, hey, you have put too little salt into this soup. Next time we will salt it, but we are not angry with each other ..."

Here the interviews highlighted another kind of trust. Its content and the direction of its development differ from the previous one. While in the previous case, trust originates from the long connections and the mutual good experiences, and in all probability it is much more fragile, in this case it is "obligatory", and originates from a selection mechanism, namely, here trust is rather a norm existing in a business network and based on personal acquaintance.

\section{CONCLUSION AND SUMMARY}

The research pointed out that the cases worded in the hypotheses really exist in Hungary. The assumptions, which were only partly answered, probably could be answered if the number of interviews would be have been increased, since this does not indicate that those cases do not exist, it shows that their relevance is smaller at the interviewed companies.

This research wanted to find an answer to the question: what is the connection between the cooperation forms and the conflict management strategies in the Hungarian supplier-customer relations? I analyzed the connections along the power differences, the type of the supplied product and the relation between the negotiating parties. In each of the cases I analyzed the measure of interest interdependence between the companies, as the social embeddedness of the companies can be deduced from it. While, on the one hand, embeddedness is at the same time the resource of the existing interdependence, as well. At the same time, the level and the form of interest interdependence determine the available strategies for the resolution of conflicts. The 
most important explanatory variable was trust functioning on inter-company and interpersonal levels.

The conclusion of the research is that the analyzed inter-company connections are not fragile in the sense that the actors rarely apply sanctions against each other, in spite of the fact that in the connections the parties are not in coequal position. The reason is that each of the interviewed companies is committed to long-term connections and endeavors to establish stable and good business connections. Consequently, the connection of business partners is not coordinated by their written contractual relation but by the so-called informal rules, norms that represent ethical norms and trust. This way the application of sanctions and the replacement of the other party are very final and rare steps, as the loss of a reliable partner represents a high risk factor. Therefore, each of the companies is committed to negotiations and to a quick solution in conflict management. "Good connection" and partnership are very important elements in business relations, consequently, in principle the possibility is given for constructive conflict management, however, there may be several obstacles to a constructive, interest-based negotiation. I gave two examples for this aspect. In the first one I pointed out that in the multinational companies the internal organizational structure did not offer any opportunity for quick and constructive conflict management; on the other hand, even in case of a total interdependence (when both the supply of and the demand for products are low) the parties applied offensive conflict management strategies; the reason for this may be that the parties are in lack of good negotiation techniques. We could meet constructive conflict management only in the case of the so-called "business elite" which is a group where one can belong to only if he meets very high requirements (institution of the first selection order), and the personal connections are based on such a deep trust that mutuality is the typical feature in problem management.

In the research several questions and problems arose which can be solved only by further research. Such are the separation the effect of the reputational interdependence (network) from the individual prestige of a company. Some important questions arose also in connection with norms, as well. It is an interesting question of how and by what informal tools the companies protect their norms and when (under what circumstances and conditions) it is worthwhile for the actors to break these norms. Furthermore, another interesting issue, how and under what conditions can new coordination norms evolve through the applied conflict management methods (e.g. negotiating tools). Another important problem is to make finer differences between interpersonal and inter-company trust and to analyze how they influence the conflict resolution strategies.

\section{REFERENCES}

Dahl, R.A. (1968): Power. In Sills, D.L. (ed.): International Encyclopaedia of the Social Sciences. Vol. 12. Old Tappan, N.J.: Macmillan.

Deutch, M. (1996): Konstruktív és destruktív folyamatok. In Lányi, G. (ed.): Politikai pszichológia. (Political Psychology). Budapest: Balassi.

Deutch, M. (2000): Cooperation and Competition, The Handbook of Conflict Resolution. San Francisco: Jossey-Bass Publishers. 
Fine, G.A. (2001): Enacting Norms: Mushrooming and the Culture of Expectations and Explanations. In Hechter, M. and Opp, K.D. (eds.): Social Norms. New York: Russel Sage Foundation.

Fisher, R., Ury, R. and Patton, B. (1997): A sikeres tárgyalás alapjai. [The Basic of Successful Negotiation.] Budapest: Bagolyvár.

Granovetter, M. (1990): The Old and the New Economic Sociology: A History and an Agenda. In Friendland, R. and Robertson, A.F. (eds.): Beyond the Marketplace: Rethinking Economy and Society. New York: Aldine de Gruyter, 95-112.

Grief, A. (1993): Contract Enforceability and Economic Institutions in Early Trade: The Magribi Traders' Coalition. The American Economic Review, 83(3): 525-548.

Halpern, J.J. (1994): The Effect of Friendship on Personal Business Transaction. Journal of Conflict Resolution, 38(4): 647-664.

Hankiss, E. (1983): Társadalmi csapdák. [Social Traps.] Budapest: Magvető.

Horne, C. (2001): Sociological Perspectives on the Emergence of Norms. In Hechter, M. and Opp, K.D. (eds.): Social Norms. New York: Russel Sage Foundation.

Krémer, A. (1999): Pozícionális és érdekalapú tárgyalás. [Positional and Interest-based Negotiations.] In Tóth, P.P. (ed.): Döntőbiráskodás. [Arbitration.] Budapest: Püski Kiadó.

Lengyel, Gy. and Szántó, Z. (1996): A gazdasági élet szociológiája. [The Sociology of Economic Life.] Budapest: Aula Kiadó.

Lewicky, R.J. and Bunker, B.B. (1995): Trust in Relationship: A Model of Development and Decline, Conflict Cooperation, and Justice. In Bunker, B.B. and Rubin, J.Z. (eds.): Essays Inspired by the Work of Morton Deutch. San Francisco: Jossey-Bass.

Lewicky, R.J. and Bunker, B.B. (1996): Developing and Maintaining Trust in Work-Relationships. In Kramer, R. and. Tyler, T.R. (eds.): Trust in Organisations: Frontiers of Theory and Research. Thousand Oaks, California: Sage.

Lewicky, R.J. and Wiethoff, C. (2000): Trust, Trust Development, and Trust Repair, The Handbook of Conflict Resolution. San Francisco: Jossey-Bass Publishers.

Lorenz, E.H. (1988): Neither Friends nor Strangers: Informal Networks of Subcontracting in French Industry. In Gambetta, D. (ed.): Trust Making and Breaking Cooperative Relations. Basil Blackwell.

Macaulay, S. (1992): Non-Contractual Relations in Business: A Preliminary Study. In Granovetter, M. and Swedberg, R. (eds.): The Sociology of Economic Life. Westview Press.

Morgan, G. (1986): Images of Organisations. London: Sage.

Radaev, V. (2002): How Trust Is Established in Economic Relationships When Institutions and Individuals Are Not Trustworthy (The Case of Russia). Collegium Budapest, 22-23. November, 2002.

Raub, W. and Weesie, J. (1990): Reputation and Efficiency In Social Interactions: An Example of Network Effects. American Journal of Sociology, 96: 626-654.

Rousseau, D., Sitkin, S.B., Burt, R.S. and Camerer, C. (1998): Not So Different After All: A Cross Discipline View of Trust. Academy of Management Review, 23: 393-404. 